\title{
Proteomic profiling of $m d x-4 c v$ serum reveals highly elevated levels of the inflammation-induced plasma marker haptoglobin in muscular dystrophy
}

\author{
SANDRA MURPHY $^{1}$, PAUL DOWLING ${ }^{1}$, MARGIT ZWEYER $^{2}$, MICHAEL HENRY $^{3}$, PAULA MELEADY $^{3}$, \\ RUSTAM R. MUNDEGAR ${ }^{2}$, DIETER SWANDULLA ${ }^{2}$ and KAY OHLENDIECK ${ }^{1}$ \\ ${ }^{1}$ Department of Biology, Maynooth University, National University of Ireland, Maynooth, Co. Kildare, Ireland; \\ ${ }^{2}$ Department of Physiology II, University of Bonn, D-53115 Bonn, Germany; \\ ${ }^{3}$ National Institute for Cellular Biotechnology, Dublin City University, Dublin 9, Ireland
}

Received November 16, 2016; Accepted March 29, 2017

DOI: $10.3892 / \mathrm{ijmm} .2017 .2952$

\begin{abstract}
X-linked muscular dystrophy is caused by primary abnormalities in the Dmd gene and is characterized by the almost complete loss of the membrane cytoskeletal protein dystrophin, which triggers sarcolemmal instability, abnormal calcium homeostasis, increased proteolysis and impaired excitation-contraction coupling. In addition to progressive necrosis, crucial secondary pathologies are represented by myofibrosis and the invasion of immune cells in damaged muscle fibres. In order to determine whether these substantial changes within the skeletal musculature are reflected by an altered rate of protein release into the circulatory system or other plasma fluctuations, we used label-free mass spectrometry to characterize serum from the $m d x-4 c v$ model of Duchenne muscular dystrophy. Comparative proteomics revealed a large number of increased vs. decreased protein species in $m d x-4 c v$ serum. A serum component with greatly elevated levels was identified as the inflammation-inducible plasma marker haptoglobin. This acute phase response protein is usually secreted in relation to tissue damage and sterile inflammation. Both immunoblot analyses and enzyme-linked immunosorbent assays confirmed the increased concentration of haptoglobin in crude $m d x-4 c v$ serum. This suggests that haptoglobin, in conjunction with other altered serum proteins, represents a novel diagnostic, prognostic and/or therapy-monitoring biomarker candidate to evaluate the inflammatory response in the $m d x-4 c v$ animal model of dystrophinopathy.
\end{abstract}

Correspondence to: Professor Kay Ohlendieck, Muscle Biology Laboratory, Department of Biology, Maynooth University, National University of Ireland, Maynooth, Co. Kildare, Ireland E-mail: kay.ohlendieck@nuim.ie

Key words: acute phase plasma protein, biomarker, dystrophin, dystrophinopathy, haptoglobin, sterile inflammation

\section{Introduction}

Duchenne muscular dystrophy is a devastating muscle wasting disease of early childhood (1) and the most frequently inherited neuromuscular disorder (2). It has an X-linked mode of inheritance and is primarily caused by abnormalities in the Dmd gene, which trigger the almost complete absence of the membrane cytoskeletal protein dystrophin of $427 \mathrm{kDa}$ (3). The loss of dystrophin results in a significant reduction of dystrophin-associated glycoproteins, which in turn impairs the linkage between the extracellular matrix component laminin and the actin membrane cytoskeleton (4). In addition to destabilizing the fibre periphery and thereby making muscle cells more susceptible to micro-rupturing during excitation-contraction-relaxation cycles (5), a variety of secondary changes play a key role in the molecular pathogenesis of X-linked muscular dystrophy (6). This includes reactive myofibrosis resulting in tissue scarring and loss of fibre elasticity, abnormal calcium regulation and increased proteolytic degradation, impaired cellular signalling and disturbed excitation-contraction coupling, as well as sterile inflammation of dystrophin-deficient muscle tissue (7-10). Therefore, the immune system appears to play a critical role in $\mathrm{X}$-linked muscular dystrophy (11-14). It is debatable whether the inflammatory pathology of dystrophic muscles is based on a reactive and relatively non-specific invasion of immune cells in damaged muscle fibres or represents a separate mechanism that promotes fibre degeneration independent of sarcolemmal destabilisation (15-17). Thus, although dystrophinopathies are triggered by a single gene defect, the pathophysiological consequences and adaptive responses of dystrophic muscles are highly complex.

In the pre-proteomic era, a variety of muscle-derived protein markers have been established for general diagnostic purposes. Serum markers with an association to tissue damage and muscular injury include creatine kinase, pyruvate kinase, hemopexin, adenylate kinase, carbonic anhydrase and lactate dehydrogenase (18-22). However, the concentration of some of these serum markers vary considerably in healthy individuals, lack a high degree of specificity and/or exhibit inconsistencies 
in their concentration changes during acute vs. chronic disease stages. This potential lack of diagnostic reliability and limited robustness restricts the clinical usefulness of many general protein biomarkers of skeletal muscle damage for accurate sample screening, prognosis or clinical outcome measures. More specific serum proteins that exhibit elevated levels in Duchenne patients seem to be the tissue inhibitors of metalloproteinase-1, transforming growth factor TGF- $\beta 1$ and the matrix metalloproteinase MMP-9 (23-26). In contrast to traditional biochemical studies that usually focus on the characterization of a restricted number of specific candidate molecules, large-scale biochemical approaches promise to gain new global insights into the molecular and cellular mechanisms of muscular dystrophy. Mass spectrometry-based proteomics is highly suitable to improve our general understanding of complex changes in dystrophinopathies (27). Systems biological methods promise to determine potential pathophysiological hierarchies and interconnectivities between differing secondary mechanisms within muscle tissues that are downstream of the pathobiochemical collapse of the dystrophin-glycoprotein complex (28). Most importantly, the systematic proteomic identification of new serum biomarkers is crucial for the improved diagnostic and prognostic evaluation of Duchenne muscular dystrophy and animal models of dystrophin deficiency (29).

In the field of muscular dystrophy research, the systematic screening of body fluids from Duchenne patients and established animal models of dystrophinopathies using proteomic technology has recently established a variety of new biomarker candidates, including fibronectin, the coagulation factor XIIIa, titin, various myosin light chain isoforms, myomesin-3, filamin-C, lysosomal-associated membrane protein LAMP1 and its accompanying vesicle proteins, aldolase, phosphoglycerate mutase, enolase, glycogen phosphorylase, fatty acid-binding protein, myoglobin, cytochrome $c$, malate dehydrogenase, fibrinogen, parvalbumin, electron transfer flavoprotein $\mathrm{A}$, troponin, $\mathrm{Ca}^{2+} /$ calmodulin-dependent protein kinase Camk2b, metalloproteinase Adamts5, troponin-1, myoglobin and heat-shock protein HSPA1A (30-39). In analogy to these studies and to establish new biomarker candidates for the improved evaluation of animal models of dystrophinopathy, we analysed serum from the dystrophic $m d x-4 c v$ mouse (40). The $m d x-4 c v$ model exhibits substantially less revertant dystrophin-positive fibres than the conventional mdx mouse (41), which is advantageous for outcome measurements in experimental treatment studies, such as exon-skipping therapy (42). Comparative proteomics of $m d x-4 c v$ vs. wild-type serum established a significantly increased concentration of the inflammation-inducible plasma marker haptoglobin (43). The elevated levels of this acute phase response protein agree with skeletal muscle damage and sterile inflammation in muscular dystrophy. This establishes haptoglobin as a novel biomarker candidate of the inflammatory response in dystrophinopathy.

\section{Materials and methods}

Materials. Immunodepletion of serum samples was carried out with Proteome Purify 2 Mouse Serum Protein Immunodepletion Resin (R\&D Systems, Inc., Minneapolis, MN, USA).
Ultrapure acrylamide stock solutions for gel electrophoresis were purchased from National Diagnostics (Atlanta, GA, USA). Invitrogen (Carlsbad, CA, USA) supplied Whatman nitrocellulose transfer membranes. The chemiluminescence substrate and protease inhibitors were obtained from Roche Diagnostics GmbH (Mannheim, Germany). Superfrost Plus positively-charged microscope slides were obtained from Menzel Glaser (Braunschweig, Germany). Sequencing grade modified trypsin and Lys-C were purchased from Promega Corp. (Madison, WI, USA). Pierce C18 Spin Columns were obtained from Thermo Fisher Scientific (Dublin, Ireland). Primary antibodies were purchased from Abcam (Cambridge, UK) (ab131236 to haptoglobin, ab14225-200 to albumin, ab52488 to lactate dehydrogenase, ab9033-1 to transferrin, ab15277 to dystrophin and ab11427 to parvalbumin) and Santa Cruz Biotechnology, Santa Cruz, CA, USA (sc-25607 to myoglobin). Chemicon International, Inc. (Temecula, CA, USA) provided peroxidase-conjugated secondary antibodies. Enzyme-linked immunosorbent assay assays (ELISA) were purchased from Abcam (ab157714 to haptoglobin and ab157711 to complement C3) and R\&D Systems (FABP-1/L-FABP). Normal goat serum and Cy3-conjugated antibodies were obtained from Jackson ImmunoResearch Laboratories, Inc. (West Grove, PA, USA). The embedding medium Fluoromount-G was obtained from Southern Biotech (Birmingham, AL, USA). A variety of other general chemicals, including bis-benzimide Hoechst-33342, were of analytical grade and obtained from Sigma Chemical Company (Dorset, UK).

Dystrophic mdx-4cv animal model of Duchenne muscular dystrophy. In order to investigate the serum proteome and identify potential biomarkers of dystrophinopathy, the $m d x-4 c v$ animal model was employed in the present study. This mouse model has been generated using $\mathrm{N}$-ethylnitrosourea to induce a premature stop codon in exon 53 of the Dmd gene (44). The $m d x-4 c v$ model has 10 -fold fewer dystrophin-positive revertant fibres (41) than the conventional mdx mouse (45) and thus its serum proteome may be more representative of the human condition. Mice were bred in the Bioresource Unit of the University of Bonn under standard conditions (46) with the authorization by the District Veterinary Office in Bonn, Germany. Tissue and organ harvesting was regularly reported to the District Veterinary Office. Serum and muscle samples from 6-month-old $m d x-4 c v$ and age-matched wild-type C57BL6 mice were obtained after sacrificing the animals by cervical dislocation. Samples were immediately quick-frozen in liquid nitrogen and stored at $-80^{\circ} \mathrm{C}$ prior to usage. Samples were transported to Maynooth University on dry ice in accordance with the Department of Agriculture (animal by-product register number 2016/16 to the Department of Biology, National University of Ireland, Maynooth).

Immunodepletion of mouse serum samples. One of the main challenges with the proteomic profiling of biofluids, particularly for serum and plasma, is the wide dynamic range of protein expression (47). Since highly abundant proteins such as albumin and $\operatorname{IgG}$ constitute the majority of plasma proteins, and this seriously interferes with the detection of low-copy-number proteins by mass spectrometry (48), many profiling studies use immunodepletion strategies to achieve an 
enriched pool of low-abundance proteins. We here used the Proteome Purify 2 Mouse Serum Protein Immunodepletion Resin to remove the highly abundant proteins albumin and IgG from the murine serum samples. In summary, $10 \mu \mathrm{l}$ of serum was added to a micro-centrifuge tube containing $1 \mathrm{ml}$ of immunodepletion resin. The tubes were placed on a rotary shaker for $1 \mathrm{~h}$ at room temperature. After the incubation period, the mixture was added to the upper chamber of a Spin-X filter unit (centrifuge tube with a $0.22-\mu \mathrm{m}$ cellulose acetate membrane) and centrifuged for $2 \mathrm{~min}$ at $2,000 \mathrm{x} \mathrm{g}$. The filtrate was collected and used for further analysis.

Sample preparation for mass spectrometry. Immunodepleted serum samples were acetone precipitated and the resulting pellets were re-suspended in label-free solubilisation buffer (6 $\mathrm{M}$ urea, $2 \mathrm{M}$ thiourea, $10 \mathrm{mM}$ Tris, $\mathrm{pH} 8.0$ in LC/MS grade water). Protein concentrations were determined by the Bradford assay system (49) and sample volumes were equalised with label-free solubilisation buffer. Samples were reduced for $30 \mathrm{~min}$ at $37^{\circ} \mathrm{C}$ with $10 \mathrm{mM}$ dithiothreitol and alkylated with $25 \mathrm{mM}$ iodoacetamide in $50 \mathrm{mM}$ ammonium bicarbonate for $20 \mathrm{~min}$ in the dark at room temperature (50). To limit alkylation of trypsin by any remaining unreacted iodoacetamide, samples were reduced with a further $10 \mathrm{mM}$ dithiothreitol for $15 \mathrm{~min}$ in the dark at room temperature. Proteolytic digestion of serum proteins to their constitutive peptides was carried out in two steps. Firstly samples were digested with sequencing grade Lys- $\mathrm{C}$ at a ratio of 1:100 (protease:protein) for $4 \mathrm{~h}$ at $37^{\circ} \mathrm{C}$, followed by dilution with four times the initial sample volume in $50 \mathrm{mM}$ ammonium bicarbonate. Secondly, samples were digested with sequencing-grade trypsin at a ratio of 1:25 (protease:protein) overnight at $37^{\circ} \mathrm{C}$ (51). Samples were acidified with $2 \%$ trifluoroacetic acid (TFA) in 20\% acetonitrile (ACN) [3:1 (v/v) dilution]. Peptide suspensions were purified using Pierce C18 Spin Columns, dried through vacuum centrifugation and suspended in loading buffer consisting of $2 \% \mathrm{ACN}$ and $0.05 \%$ TFA in LC-MS grade water. Samples were vortexed and sonicated to ensure an even suspension of peptides prior to mass spectrometric analysis.

Label-free liquid chromatography mass spectrometric analysis. The label-free liquid chromatography mass spectrometric (LC-MS/MS) analysis of $m d x-4 c v$ vs. wild-type serum samples was carried out using an Ultimate 3000 NanoLC system (Dionex Corporation, Sunnyvale, CA, USA) coupled to a Q-Exactive mass spectrometer (Thermo Fisher Scientific). Peptide mixtures (5 $\mu \mathrm{l}$, corresponding to $1 \mu \mathrm{g}$ protein) were loaded by an autosampler onto a C18 trap column (C18 PepMap, $300 \mu \mathrm{m}$ id x $5 \mathrm{~mm}, 5 \mu \mathrm{m}$ particle size, 100 A pore size; Thermo Fisher Scientific). The trap column was switched on-line with an analytical Biobasic C18 Picofrit column (C18 PepMap, $75 \mu \mathrm{m}$ id x $50 \mathrm{~cm}, 2 \mu \mathrm{m}$ particle size, 100 A pore size; Dionex Corporation). Serum-derived peptides were eluted using the following gradient (solvent A: $80 \%$ (v/v) ACN and $0.1 \%$ (v/v) formic acid in LC-MS grade water): $5 \%$ solvent A for $120 \mathrm{~min}, 45 \%$ solvent A for $2.5 \mathrm{~min}, 90 \%$ solvent A for 9 min and 3\% solvent A for 43 min (52). The column flow rate was set to $0.3 \mu \mathrm{l} / \mathrm{min}$. Data were acquired with Xcalibur software (Thermo Fisher Scientific). The Q-Exactive was operated in positive and data-dependent mode and was externally calibrated. Survey MS scans were conducted in the 300-1,700 m/z range with a resolution of $140,000(\mathrm{~m} / \mathrm{z} 200)$ and lock mass set to 445.12003. Collision-induced dissociation fragmentation was carried out with the 15 most intense ions per scan and at 17,500 resolution. Within $30 \mathrm{sec}$, a dynamic exclusion window was applied. An isolation window of $2 \mathrm{~m} / \mathrm{z}$ and one microscan were used to collect suitable tandem mass spectra.

Quantitative proteomic profiling by label-free LC-MS/MS analysis. Quantitative analysis of the raw data generated from LC-MS/MS was conducted with Progenesis QI for Proteomics software (version 3.1; Nonlinear Dynamics, Ltd., Newcastle upon Tyne, UK). A reference run was selected based on the highest number of peptide ions and the retention times of all the other runs were aligned to this reference run. This accounted for any drift in LC retention time, thus giving an adjusted retention time for all runs in the analysis (53). The data were filtered using the criteria listed below and were then exported as a Mascot generic file to Proteome Discoverer 2.0 (Thermo Scientific); i) peptide features with ANOVA $\leq 0.05$ between experimental groups, ii) mass peaks with charge states from ${ }^{+} 1$ to ${ }^{+} 5$ and iii) greater than one isotope per peptide. The exported MS/MS spectra from Progenesis software were used for peptide identification using Proteome Discoverer 2.0 against Mascot (version 2.3) and Sequest HT and searched against the UniProtKB-SwissProt database (taxonomy: Mus musculus). The following search parameters were used for protein identification: i) peptide mass tolerance set to $10 \mathrm{ppm}$, ii) $\mathrm{MS} / \mathrm{MS}$ mass tolerance set to $0.02 \mathrm{Da}$, iii) up to two missed cleavages were allowed, iv) carbamidomethylation set as a fixed modification and v) methionine oxidation set as a variable modification (54). For re-importation back into Progenesis LC-MS software for further analysis, only peptides classified as high confidence peptides and with ion scores of 40.00 or more (from Mascot) and/or XCorr scores $>1.5$ for singly charged ions, $>2.0$ for doubly charged ions and $>3.0$ for triply charged ions (Sequest HT, Thermo Fisher Scientific) were selected. The following criteria were applied to assign a protein as properly identified and with differential abundance: i) an ANOVA score between experimental groups of $\leq 0.05$, and ii) proteins with $\geq 2$ peptides matched (55). The PANTHER database of protein families (http://pantherdb.org; version 10.0) was used to group proteins based on their protein class (56).

Immunoblot analysis. Immunoblotting using a panel of select antibodies was used for the independent verification of the proteomic findings. Immunoblotting was performed using routine conditions as previously described in detail (57). Briefly, crude serum samples were separated by gel electrophoresis using $10 \% 1 \mathrm{D}$ polyacrylamide gels, followed by wet transfer to nitrocellulose membranes at $100 \mathrm{~V}$ for $70 \mathrm{~min}$ at $4{ }^{\circ} \mathrm{C}$ in a Trans-Blot cell from Bio-Rad Laboratories (Richmond, CA, USA). Transfer efficiency was assessed using Ponceau reversible stain and membranes were then blocked for $1 \mathrm{~h}$ at room temperature using a milk protein solution $[2.5 \%(\mathrm{w} / \mathrm{v})$ fat-free milk powder in phosphate buffered saline] (58). Membranes were incubated with appropriately diluted primary antibodies overnight at $4^{\circ} \mathrm{C}$ with gentle agitation. Membranes 
were then washed with the milk protein solution twice for 10 min and incubated with peroxidase-conjugated secondary antibodies for $1.5 \mathrm{~h}$ at room temperature with gentle agitation. Following a series of washing steps with the milk protein solution and phosphate-buffered saline, antibody-labelled protein bands were visualised using enhanced chemiluminescence. Densitometric scanning and statistical analysis of immunoblots were performed using a HP PSC-2355 scanner and ImageJ software [National Institutes of Health (NIH), Bethesda, MA, USA] along with Graph-Pad Prism software (San Diego, CA, USA), in which a $\mathrm{P}<0.05$ was deemed to be statistically significant.

ELISA. ELISA was employed to independently verify key findings from the mass spectrometric analysis. Crude serum samples were screened using quantitative sandwich enzyme immunoassays to haptoglobin, FABP-1 and complement C3. Appropriately diluted serum samples (1:400 for FABP-1, 1:1,000 for haptoglobin, and 1:30,000 for complement C3 assay) were added to antibody-coated microtiter wells and were incubated at room temperature for $20 \mathrm{~min}$ (for complement $\mathrm{C}$ and haptoglobin) or $2 \mathrm{~h}$ (for FABP-1). After the incubation period, wells were washed and a peroxidase-labelled secondary detector antibody was added. After incubation at room temperature for $20 \mathrm{~min}$ in the dark, tetramethylbenzidine chromogen substrate was added. The reaction was stopped after $10 \mathrm{~min}$ (for complement $\mathrm{C}$ and haptoglobin) or $30 \mathrm{~min}$ (for FABP-1) and absorbance was measured at $\lambda=450 \mathrm{~nm}$ on a microplate reader (33). The quantity of protein in the test samples was interpolated from the standard curve and was corrected for sample dilution. All ELISA assays were carried out with crude serum from wild-type $(\mathrm{n}=5)$ and $m d x-4 c v(\mathrm{n}=8$ for complement $\mathrm{C} 3 ; \mathrm{n}=7$ for haptoglobin and FABP-1) mice. All test samples were assayed in triplicate. The intra-plate \% CV was calculated and was found to be less than $10 \%$ for all assays. Statistical ROC (receiver operating characteristics) analyses were performed using MedCalc for Windows, version 16.8 (MedCalc Software BVBA, Ostend, Belgium) to determine representaive AUC values for individual ELISA assays.

Immunofluorescence microscopy. To establish the mutant and dystrophic status of $m d x-4 c v$ mice at the age of 6 months, deficiency in the dystrophin protein isoform Dp427 and histological skeletal muscle changes were established by immunofluorescence microscopy and histological analysis, respectively (59). Dystrophic $m d x-4 c v$ and wild-type gastrocnemius muscles were freshly dissected and then quick-frozen in liquid nitrogen. Histochemical staining was carried out with routine haematoxylin and eosin staining. Cryo-sectioning was employed to generate $10 \mu \mathrm{m}$ muscle tissue sections, which were placed on Superfrost Plus positively-charged microscope slides. Skeletal muscle cryosections were then boiled to reduce background staining (60) and permeabilized in $0.1 \%$ (v/v) Triton X-100 in phosphate-buffered saline for $30 \mathrm{~min}$ at room temperature (61). Tissue sections were blocked in $20 \%(\mathrm{v} / \mathrm{v})$ normal goat serum in phosphate-buffered saline for $30 \mathrm{~min}$ and incubated overnight at $4^{\circ} \mathrm{C}$ with an appropriately diluted antibody to dystrophin. Following a careful washing step, skeletal muscle sections were incubated with Cy3-conjugated anti-IgG antibodies (1:200) for $30 \mathrm{~min}$ at room temperature. Primary antibodies were omitted for control staining. Antibody-labelled skeletal muscle sections were embedded in Fluoromount-G medium and viewed under a Zeiss Axioskop 2 epi-fluorescence microscope equipped with a digital Zeiss AxioCam HRc camera (Carl Zeiss Jena $\mathrm{GmbH}$, Jena, Germany).

\section{Results}

In order to evaluate whether the dystrophic phenotype of the $m d x-4 c v$ mouse is reflected by an altered rate of protein release into the circulatory system or other plasma fluctuations, potential changes in the $m d x$ - $4 c v$ serum proteome were determined by label-free mass spectrometry. Key findings from the proteomic profiling of serum samples were verified by comparative immunoblotting and enzyme-linked immunosorbent assays.

Dystrophic mdx-4cv model of dystrophinopathy. Prior to the proteomic profiling of serum samples, the mutant and dystrophic status of the 6-month-old $m d x-4 c v$ animal model of Duchenne muscular dystrophy was established using immunofluorescence microscopy and histological assessment. Fig. 1 clearly demonstrates the dystrophic phenotype of the $m d x-4 c v$ gastrocnemius muscle (45). In contrast to the relatively regular cell shape and peripheral nucleation in wild-type (wt) mouse muscle (Fig. 1A), transverse sections of the $m d x-4 c v$ mouse muscle showed central nucleation and the infiltration of immune cells in areas of fibre damage (Fig. 1B). The peripheral labelling of dystrophin isoform Dp427 in wt muscle by immunofluorescence microscopy (Fig. 1C) was in stark contrast to the lack of dystrophin staining in $m d x-4 c v$ mutant muscle (Fig. 1D).

Pre-fractionation of $m d x-4 c v$ serum. Protein depletion, pre-fractionation and post-fractionation are routinely employed methods in proteomic studies of body fluids that exhibit a complex proteome with the presence of a few highly abundant proteins. These protein species may mask the detection of low-copy-number protein species. Albumin and IgG molecules are major classes of abundant plasma proteins and may therefore interfere with the detection of low-abundance proteins in comparative proteomic studies (48). We therefore employed an immunodepletion strategy to reduce sample complexity and enrich the starting material in serum proteins with a relatively low concentration (62).

In general, immunodepletion is a widely employed and internationally accepted approach for studying complex biofluids (63). This protein depletion technique decisively reduces the problem of dynamic range in both LC-MS/MS and gel-based biomarker studies (64-68). However, albumin and other major plasma proteins have been shown to bind a diverse range of minor peptides and proteins and thus the albuminand IgG-depleted serum proteome may be slightly altered in relation to the composition of select protein species (69-71), in what is generally referred to as the 'carrier-and-cargo' effect of the albuminome.

Thus, although albumin/IgG depletion can result in a concomitant decrease in certain low-molecular-mass proteins due to their biological interactions with albumin or $\operatorname{IgG}$ 


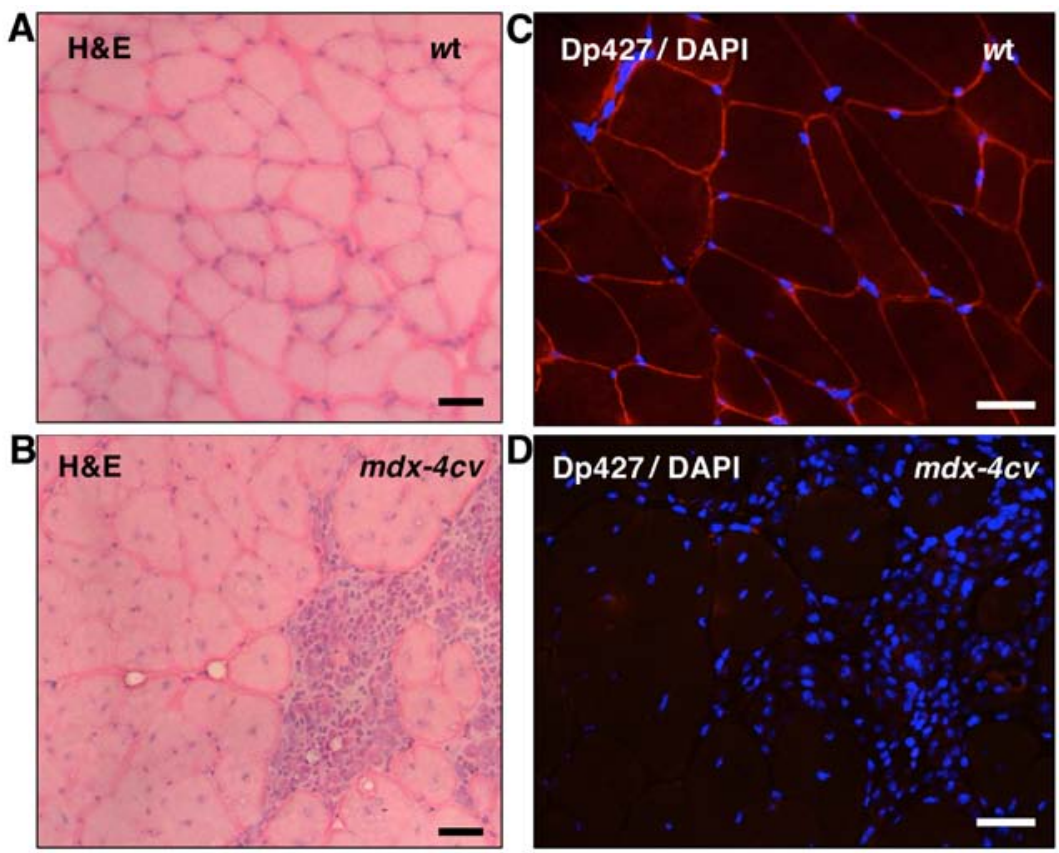

Figure 1. Histological and immunofluorescence microscopic analysis of 6-month-old $m d x$ - $4 c v$ mouse gastrocnemius muscle. Shown are histological staining with haematoxylin and eosin (A and B) and immunofluorescence labelling with an antibody to dystrophin isoform Dp427 (C and D) of muscle sections from wild-type (A and C) vs. $m d x-4 c v$ (B and D) mouse gastrocnemius muscle. Scale bars represent 10 and $40 \mu \mathrm{m}$ in panels (A and B) and (C and D), respectively.

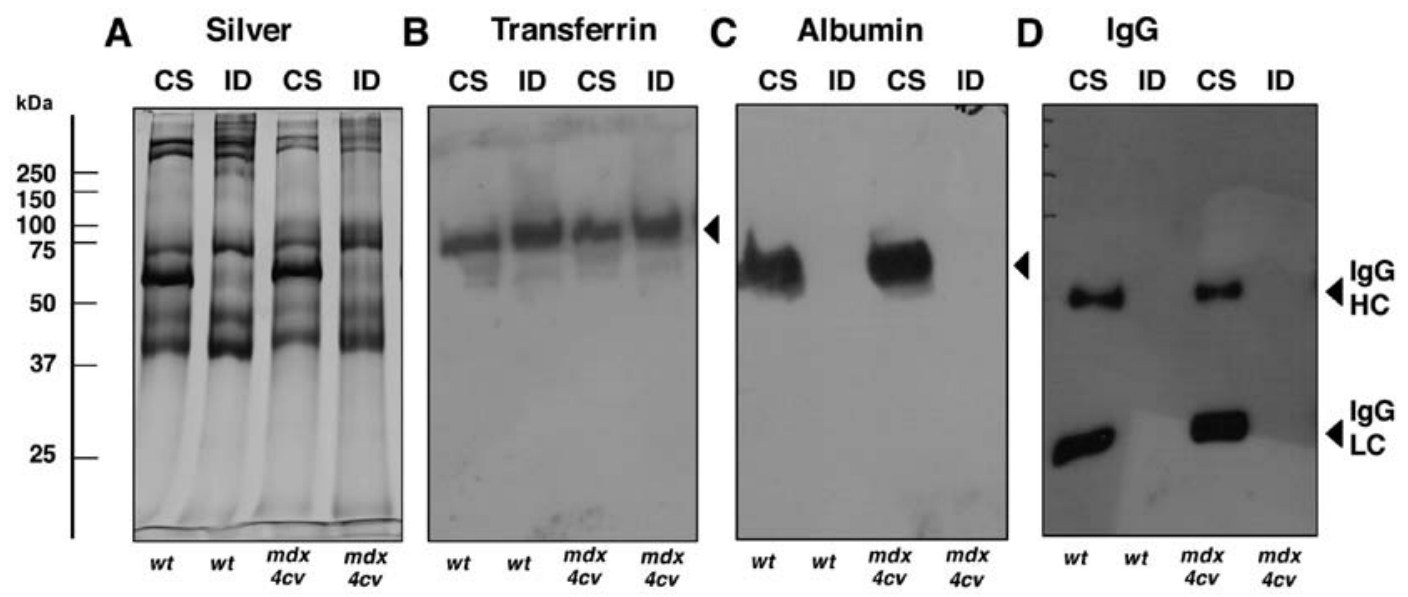

Figure 2. Immunoblot analysis of the pre-fractionation immunodepletion of $m d x-4 c v$ mouse serum. Prior to the proteomic screening of $m d x-4 c v$ serum, immunodepletion was used to reduce sample complexity and enrich the starting material in serum proteins with a relatively low concentration. Shown is a silver-stained gel (A) and corresponding immunoblots labelled with antibodies to transferrin (B), albumin (C) and $\operatorname{IgG}$ (D). Lanes 1 to 4 represent 6-month-old wild-type vs. $m d x-4 c v$ crude serum (CS) and immuno-depleted serum (ID), respectively. Molecular mass standards are marked at the left of the panels.

molecules, the analytical advantages of reducing sample complexity outweigh this issue (62). Fig. 2 illustrates the successful depletion of albumin and $\mathrm{IgG}$ from the crude serum samples derived from dystrophic $m d x-4 c v$ mice and wild-type animals. A representative silver-stained gel confirmed the alteration in the overall protein composition of crude serum vs. immuno-depleted serum (Fig. 2A). In contrast to transferrin, for which the abundance was not highly altered following pre-fractionation (Fig. 2B), the amounts of albumin, IgG heavy chain and IgG light chain were markedly decreased in the immuno-depleted fractions (Fig. 2C and D).

Proteomic profiling of 6-month-old $m d x-4 c v$ serum. The proteomic profiling approach used in the present study is summarized in the flow chart of Fig. 3. Following pre-fractionation, the albumin/IgG-depleted serum from wild-type vs. dystrophic $m d x-4 c v$ mice was analysed by comparative label-free mass spectrometry to establish the serum signature of dystrophinopathy. The proteomic survey of 2 technical repeats each of 4 biological samples identified 461 changed serum protein species consisting of 360 increased and 101 decreased proteins in $m d x-4 c v$ serum. As an illustrative example, the crucial proteomic identification and mass spectrometric fingerprint of the acute response phase protein haptoglobin (Q61646) is shown in Fig. 3. The independent verification of key proteomic findings was carried out by immunoblotting and enzyme-linked immunosorbent assays, as outlined below. Identified proteins with a high degree 
Table I. List of increased proteins in 6-month-old $m d x-4 c v$ mouse serum vs. age-matched wild-type mouse serum as determined by label-free mass spectrometry.

\begin{tabular}{llccc}
\hline Accession no. & \multicolumn{1}{c}{ Protein name } & Unique peptides & Confidence score & Fold change \\
\hline P70441 & Na(+)/H(+) exchange regulatory cofactor NHE-RF1 & 2 & 128.77 & 384.8 \\
Q9D5J6 & Sedoheptulokinase & 3 & 181.59 & 213.1 \\
Q19LI2 & a-1B-glycoprotein & 3 & 201.11 & 199.9 \\
Q99020 & Heterogeneous nuclear ribonucleoprotein A/B & 2 & 120.87 & 131.4 \\
P09405 & Nucleolin & 2 & 66.85 & 104.3 \\
Q62446 & Peptidyl-prolyl cis-trans isomerase FKBP3 & 2 & 69.16 & 89.1 \\
Q8BG05 & Heterogeneous nuclear ribonucleoprotein A3 & 2 & 132.17 & 72.8 \\
Q08331 & Calretinin & 5 & 174.3 & 59.9 \\
P07361 & a-1-acid glycoprotein 2 & 2 & 101.47 & 56.8 \\
P00493 & Hypoxanthine-guanine phosphoribosyltransferase & 2 & 73.54 & 53.3 \\
Q61646 & Haptoglobin & 14 & 826.52 & 50.3 \\
Q9D0R2 & Threonine-tRNA ligase, cytoplasmic & 5 & 187.79 & 48.4 \\
P48428 & Tubulin-specific chaperone A & 2 & 59.15 & 46.8 \\
Q99KP3 & Lambda-crystallin homolog & 3 & 173.73 & 43.3 \\
A2ABU4 & Myomesin-3 & 9 & 588.37 & 38.6 \\
Q99KC8 & von Willebrand factor A domain-containing protein 5A & 2 & 41.66 & 37.2 \\
P05366 & Serum amyloid A-1 protein & 2 & 135.98 & 36.9 \\
Q8VC12 & Urocanate hydratase & 10 & 751.33 & 36.9 \\
P47199 & Quinone oxidoreductase & 4 & 206.42 & 36.8 \\
Q91X52 & L-xylulose reductase & 2 & 99.38 & 32.8 \\
Q8VCX1 & 3-oxo-5- $\beta$-steroid 4-dehydrogenase & 5 & 177.09 & 31.2 \\
Q9WTP6 & Adenylate kinase 2, mitochondrial & 2 & 67.03 & 31.2 \\
A3KMP2 & Tetratricopeptide repeat protein 38 & 4 & 177.89 & 30.6 \\
Q5SX40 & Myosin-1 & 62 & 4670.12 & 30.3 \\
A2ASS6 & Titin & 88 & 4357.28 & 30.2 \\
P99027 & 60S acidic ribosomal protein P2 & 2 & 162.5 & 30.1 \\
Q8VCT4 & Carboxylesterase 1D & 5 & 114.1 & 26.8 \\
P53026 & 60S ribosomal protein L10a & 2 & 97.35 & 26.5 \\
P68040 & Guanine nucleotide-binding protein subunit $\beta$-2-like 1 & 2 & 252.9 & 25.6 \\
Q9QXE0 & 2-Hydroxyacyl-CoA lyase 1 & 4 & & 24.5 \\
\hline & & & & \\
\hline
\end{tabular}

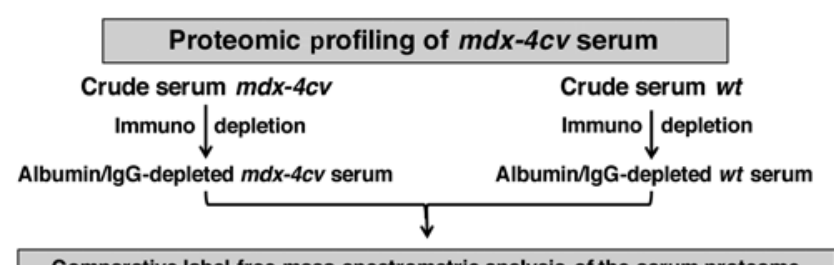

Comparative label-free mass spectrometric analysis of the serum proteome

MS analysis: 2 technical repeats each of 4 biological repeats: $m d x-4 c v$ vs. $w t$

$\downarrow$

Proteomic identification of 461 changed serum protein species:

- 360 increased proteins in $m d x-4 c v$ serum

- 101 decreased proteins in $m d x-4 v$ serum

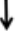

Serum signature of dystrophinopathy

Proteomic identification of the acute response phase protein haptoglobin (Q61646)

mralgavvt lllwgql favel gndamdfeddscpkppeiangyvehlvryrcrqf yrLRA EGDGVYTLNDEKOWVNTVAGEKLPECEAVCGKPKhpvdqv $r$ IIGGSMDAKGSFPWOAK isrHGLTTGATLISDOWLLTTAKn 1 f lnhsetas akDITPTLTLYVGKNOLVE IEKVV 1 h

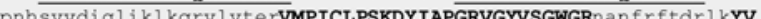
pI MLPVADQDKcvvhyenstvpekknltspvgvqpilneht fcagl tkyqedtcygdagsa ai hdmeedt wyaagils fdkSCAVAEYGVYVRATDLKDWVQETMAK of increase vs. decrease are listed in Tables I-III, respectively. The tables list information in relation to accession number, protein name, number of unique peptides, confidence score and fold change.

The most markedly elevated levels included $\mathrm{Na}^{+} / \mathrm{H}^{+}$exchange regulatory cofactor NHE-RF1, sedoheptulokinase, $\alpha$-1B-glycoprotein, heterogeneous nuclear ribonucleoprotein $\mathrm{A} / \mathrm{B}$ and $\mathrm{A} 3$, nucleolin, peptidyl-prolyl cis-trans isomerase FKBP3, calretinin, $\alpha$-1-acid glycoprotein 2, hypoxanthine-guanine phosphoribosyl-transferase, haptoglobin, cytoplasmic threonine-tRNA ligase, tubulin-specific chaperone A, lambda-crystallin homolog, myomesin-3, von Willebrand factor A domain-containing protein $5 \mathrm{~A}$, serum

Figure 3. Overview of the proteomic strategy to determine global changes in the protein constellation of $m d x-4 c v$ mouse serum. The flow chart outlines the comparative analysis of wild-type vs. $m d x-4 c v$ serum samples and shows the mass spectrometric fingerprint of the acute phase plasma protein haptoglobin as a major finding of this proteomic study 
Table II. List of previously established increased serum marker proteins that were also identified in 6-month-old $m d x$ - $4 c v$ mouse serum vs. age-matched wild-type mouse serum by label-free mass spectrometry.

\begin{tabular}{|c|c|c|c|c|}
\hline Accession no. & Protein name & Unique peptides & Confidence score & Fold change \\
\hline Q05816 & Fatty acid-binding protein, epidermal & 8 & 385.47 & 18.3 \\
\hline P13412 & Troponin I, fast skeletal muscle & 3 & 131.21 & 18.2 \\
\hline P62897 & Cytochrome c, somatic & 5 & 543.08 & 15.2 \\
\hline P05063 & Fructose-bisphosphate aldolase $\mathrm{C}$ & 9 & 679.32 & 14.8 \\
\hline P05977 & Myosin light chain $1 / 3$, skeletal muscle isoform & 9 & 561.43 & 12.0 \\
\hline P52480 & Pyruvate kinase PKM & 46 & 4564.3 & 10.4 \\
\hline Q9ET01 & Glycogen phosphorylase, liver form & 36 & 2184.82 & 9.7 \\
\hline P12710 & Fatty acid-binding protein, liver & 11 & 928.62 & 8.4 \\
\hline Q04447 & Creatine kinase B-type & 17 & 1492.20 & 8.2 \\
\hline P11499 & Heat shock protein HSP $90-\beta$ & 4 & 202.62 & 7.6 \\
\hline Q9WUB3 & Glycogen phosphorylase, muscle form & 48 & 4290.78 & 7.0 \\
\hline Q91Y97 & Fructose-bisphosphate aldolase B & 20 & 1745.78 & 6.4 \\
\hline P17183 & $\gamma$-enolase & 6 & 437.74 & 5.7 \\
\hline P08249 & Malate dehydrogenase, mitochondrial & 6 & 274.29 & 5.7 \\
\hline P20801 & Troponin C, skeletal muscle & 3 & 192.78 & 5.6 \\
\hline Q9D0F9 & Phosphoglucomutase-1 & 22 & 1318.77 & 4.0 \\
\hline Q61316 & Heat shock $70 \mathrm{kDa}$ protein 4 & 20 & 1146.72 & 3.9 \\
\hline P53657 & Pyruvate kinase PKLR & 3 & 119.98 & 3.7 \\
\hline Q6P8J7 & Creatine kinase S-type, mitochondrial & 10 & 596.62 & 3.7 \\
\hline P14602 & Heat shock protein $\beta-1$ & 3 & 150.33 & 3.3 \\
\hline P14152 & Malate dehydrogenase, cytoplasmic & 13 & 1108.02 & 3.3 \\
\hline P05064 & Fructose-bisphosphate aldolase A & 30 & 3015.5 & 3.1 \\
\hline P16125 & L-lactate dehydrogenase B chain & 12 & 1000.89 & 2.9 \\
\hline P07901 & Heat shock protein HSP $90-\alpha$ & 4 & 172.93 & 2.8 \\
\hline P17182 & $\alpha$-enolase & 25 & 1951.59 & 2.7 \\
\hline P32848 & Parvalbumin $\alpha$ & 16 & 1096.30 & 2.6 \\
\hline P63017 & Heat shock cognate $71 \mathrm{kDa}$ protein & 18 & 1479.96 & 2.5 \\
\hline P16015 & Carbonic anhydrase 3 & 15 & 830.57 & 2.4 \\
\hline P07310 & Creatine kinase M-type & 30 & 2895.13 & 2.4 \\
\hline P11276 & Fibronectin & 6 & 298.37 & 2.3 \\
\hline P04117 & Fatty acid-binding protein, adipocyte & 9 & 800.82 & 2.2 \\
\hline Q9R0Y5 & Adenylate kinase isoenzyme 1 & 3 & 247.3 & 2.2 \\
\hline $\mathrm{O} 70250$ & Phosphoglucomutase 2 & 10 & 714.82 & 2.2 \\
\hline P21550 & $\beta$-enolase & 23 & 2090.28 & 2.1 \\
\hline P11404 & Fatty acid-binding protein, heart & 5 & 281.57 & 1.6 \\
\hline Q91X72 & Hemopexin & 32 & 2684.29 & 1.5 \\
\hline O88783 & Coagulation factor $\mathrm{V}$ & 6 & 223.63 & 1.3 \\
\hline
\end{tabular}

amyloid A-1 protein, urocanate hydratase, quinone oxidoreductase, L-xylulose reductase, 3-oxo-5- $\beta$-steroid 4-dehydrogenase, mitochondrial adenylate kinase 2 , tetratricopeptide repeat protein 38 , myosin-1 and titin. A very interesting finding was the identification of increased haptoglobin, which represents a typical acute phase plasma marker protein of tissue damage and the inflammatory response. The elevated concentration of haptoglobin was further investigated by immuno-labelling approaches, as outlined below. Besides serum haptoglobin, elevated levels of another acute phase plasma protein were established for amyloid A-1 protein (Table I).

Importantly, a variety of common serum markers of dystrophinopathy were verified by mass spectrometry
(Tables I and II), including increased amounts of creatine kinase isoforms CK-B, CK-S and CK-M, pyruvate kinase isoforms PKM and PKLR, hemopexin, adenylate kinase isoforms AK1 and AK2, carbonic anhydrase isoform CA3 and lactate dehydrogenase, which have been previously established by non-proteomic techniques (18-22). Elevated levels of previously identified proteomic serum markers were also confirmed (Tables I and II), such as fibronectin, coagulation factor V, titin, myosin light chain $1 / 3$, fructose-bisphosphate aldolase (isoforms A-C), phosphoglucomutase (isoforms 1 and 2), enolase (isoforms $\alpha, \beta$ and $\gamma$ ), glycogen phosphorylase (muscle and liver isoforms), fatty acid-binding protein (adipocyte, epidermal, liver and heart isoforms), cytochrome $c$, malate 
Table III: List of decreased proteins in 6-month-old $m d x-4 c v$ mouse serum vs. age-matched wild-type mouse serum exhibiting a fold-change above 2 as determined by label-free mass spectrometry.

\begin{tabular}{llccc}
\hline Accession no. & & Unique peptides & Confidence score & Fold change \\
\hline P09470 & Angiotensin-converting enzyme & 2 & 97.76 & 3.5 \\
O35930 & Platelet glycoprotein Ib $\alpha$ chain & 11 & 865.35 & 3.4 \\
Q07456 & Protein AMBP & 4 & 362.51 & 3.1 \\
P28665 & Murinoglobulin-1 & 116 & 12973.81 & 2.9 \\
B5X0G2 & Major urinary protein 17 & 5 & 231.6 & 2.8 \\
Q00898 & $\alpha$-1-antitrypsin 1-5 & 14 & 1024.28 & 2.7 \\
P05208 & Chymotrypsin-like elastase family member 2A & 3 & 230.49 & 2.7 \\
O08742 & Platelet glycoprotein V & 5 & 601.56 & 2.6 \\
Q03311 & Cholinesterase & 7 & 362.36 & 2.6 \\
P01942 & Hemoglobin subunit $\alpha$ & 7 & 448.81 & 2.6 \\
P42703 & Leukemia inhibitory factor receptor & 28 & 2444.33 & 2.5 \\
Q62351 & Transferrin receptor protein 1 & 5 & 278.54 & 2.5 \\
Q9DBB9 & Carboxypeptidase N subunit 2 & 15 & 1509.87 & 2.4 \\
Q8QZR3 & Pyrethroid hydrolase Ces2a & 2 & 114.66 & 2.4 \\
Q8BPB5 & EGF-containing fibulin-like extracellular matrix protein 1 & 4 & 182.66 & 2.4 \\
O88968 & Transcobalamin-2 & 9 & 577.32 & 2.4 \\
Q61704 & Inter- $\alpha$-trypsin inhibitor heavy chain H3 & 7 & 627.52 & 2.3 \\
Q03734 & Serine protease inhibitor A3M & 9 & 788.27 & 2.3 \\
E9Q414 & Apolipoprotein B-100 & 35 & 1947.84 & 2.3 \\
Q07235 & Glia-derived nexin & 5 & 234.21 & 2.3 \\
\hline
\end{tabular}

\section{Proteins with increased abundance in $m d x-4 c v$ serum}

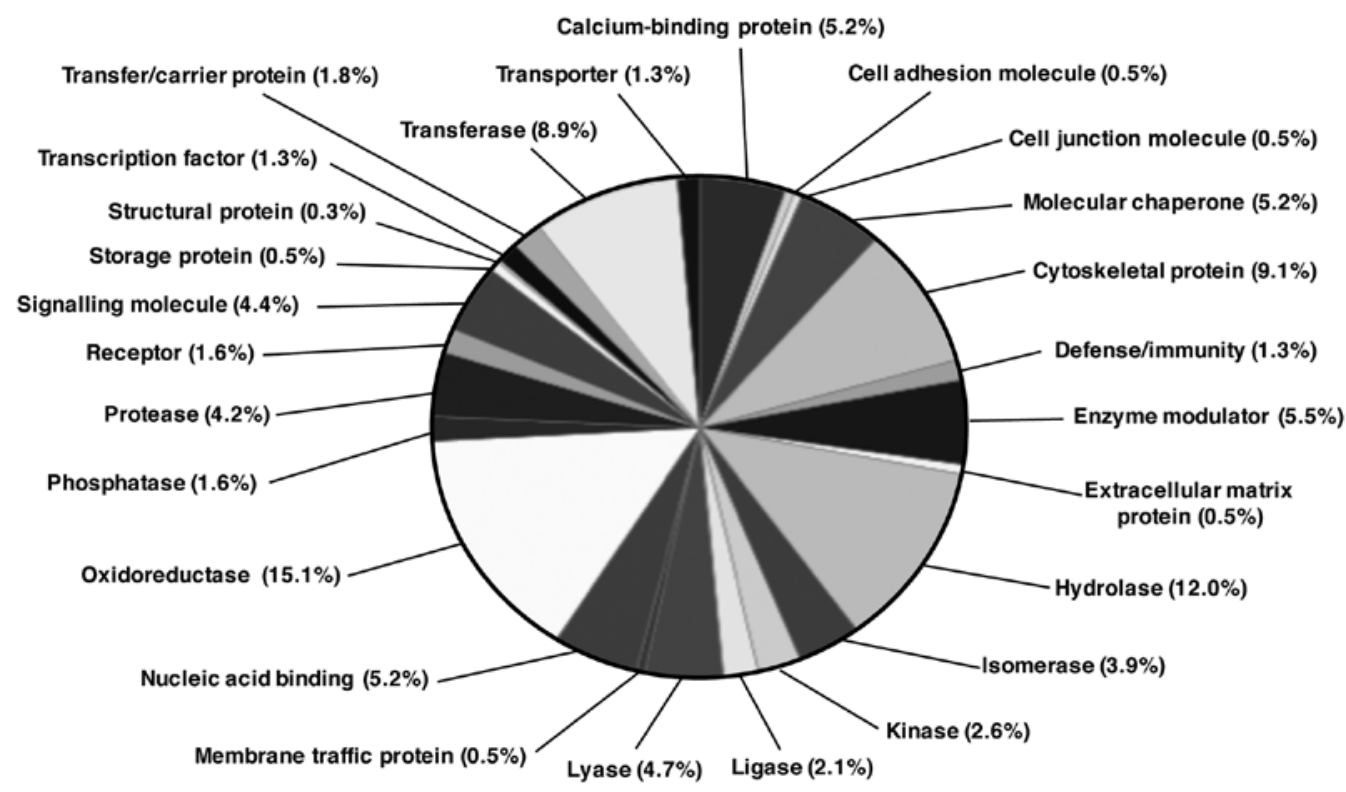

Figure 4. Summary of increased protein classes in $m d x-4 c v$ mouse serum. The bioinformatic software programme PANTHER (56) was employed to establish the clustering of protein classes based on the mass spectrometric analysis of the albumin/IgG-depleted protein fraction from $m d x-4 c v$ serum vs. wild-type serum (Tables I and II).

dehydrogenase (cytoplasmic and mitochondrial isoform), parvalbumin, troponin (muscle isoforms $\mathrm{TnI}$ and $\mathrm{TnC}$ ) and various heat-shock proteins (HSP90- $\beta$, HSP90- $\alpha$, HSP70, HSP $\beta-1$, HSP cognate 71) (30-39). These findings demonstrate the reproducibility of the findings from a large number of biochemical and proteomic surveys of serum and plasma preparations from dystrophic patients and animal models of Duchenne muscular dystrophy.

The degree of decreased serum proteins was markedly less pronounced as compared to the increased protein species. 


\section{Proteins with decreased abundance in $m d x-4 c v$ serum}

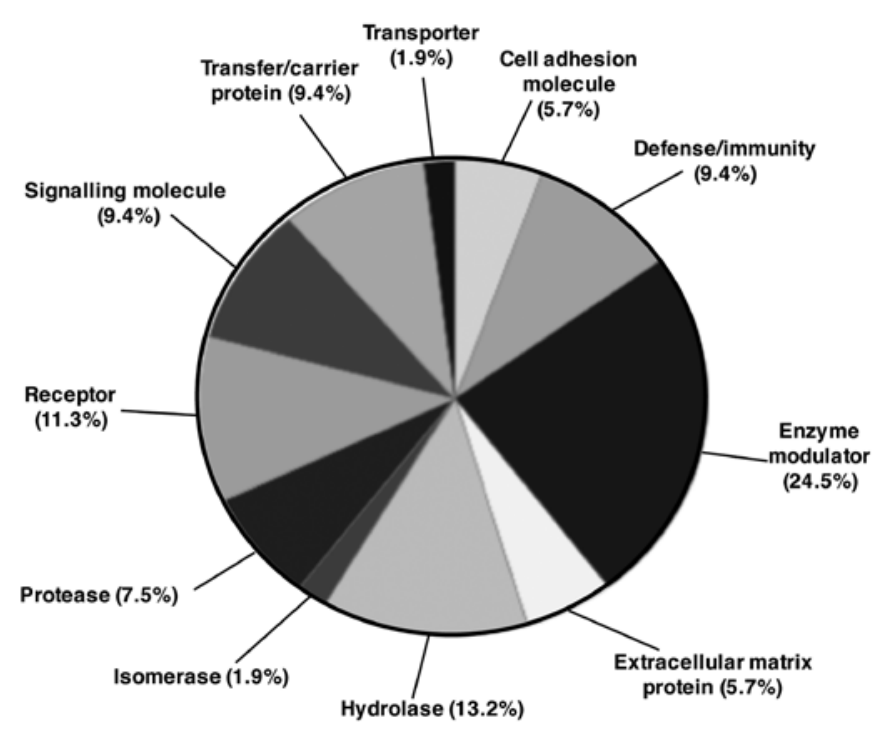

Figure 5. Summary of decreased protein classes in $m d x$ - $4 c v$ mouse serum. The bioinformatic software programme PANTHER (56) was employed to establish the clustering of protein classes based on the mass spectrometric analysis of the albumin/IgG-depleted protein fraction from $m d x-4 c v$ serum vs. wild-type serum (Table III).
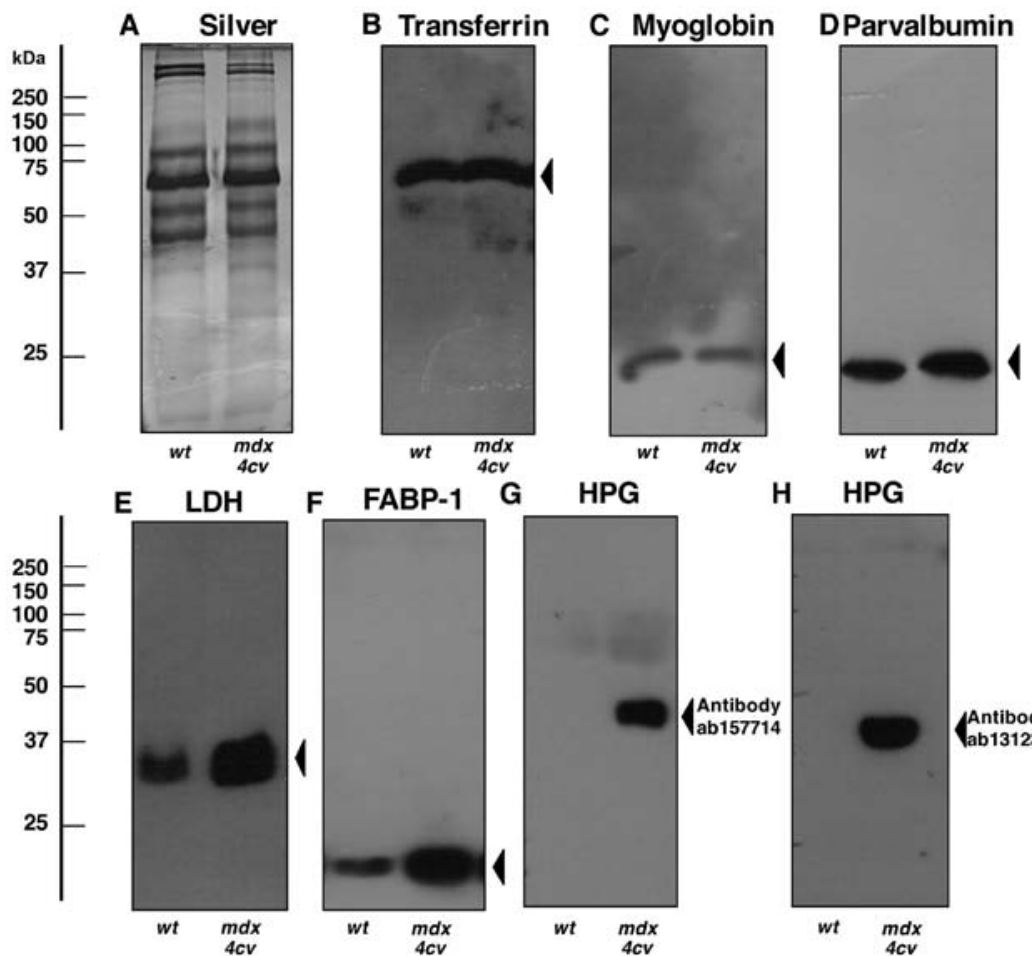

HPG

Figure 6. Immunoblot survey of proteins in $m d x-4 c v$ mouse serum. Shown is a (A) silver-stained gel and corresponding immunoblots labelled with antibodies to (B) transferrin, (C) myoglobin, (D) parvalbumin, (E) LDH, (F) FABP-1 and (G and H) HPG. HPG expression was evaluated with 2 different antibodies, (G) ab157714 and (H) ab131236. Lanes 1 and 2 represent crude serum from 6-month-old wild-type (wt) vs. dystrophic $m d x$ - $4 c v$ mice, respectively. Molecular mass standards are marked at the left of the panels. LDH, lactate dehydrogenase; FABP, fatty acid binding protein; HPG, haptoglobin.

Moderately reduced levels were shown to include angiotensin-converting enzyme, platelet glycoprotein $\mathrm{Ib} \alpha$ chain, protein AMBP, murinoglobulin-1, major urinary protein 17, $\alpha$-1-antitrypsin $1-5$, chymotrypsin-like elastase family member 2A, platelet glycoprotein $\mathrm{V}$, cholinesterase, hemoglobin subunit $\alpha$, leukemia inhibitory factor receptor, transferrin receptor protein 1 and carboxypeptidase $\mathrm{N}$ subunit 2 (Table III). Figs. 4 and 5 show the bioinformatic PANTHER analysis of protein families (56) that were established to exhibit an altered concentration in $m d x-4 c v$ mouse serum. 

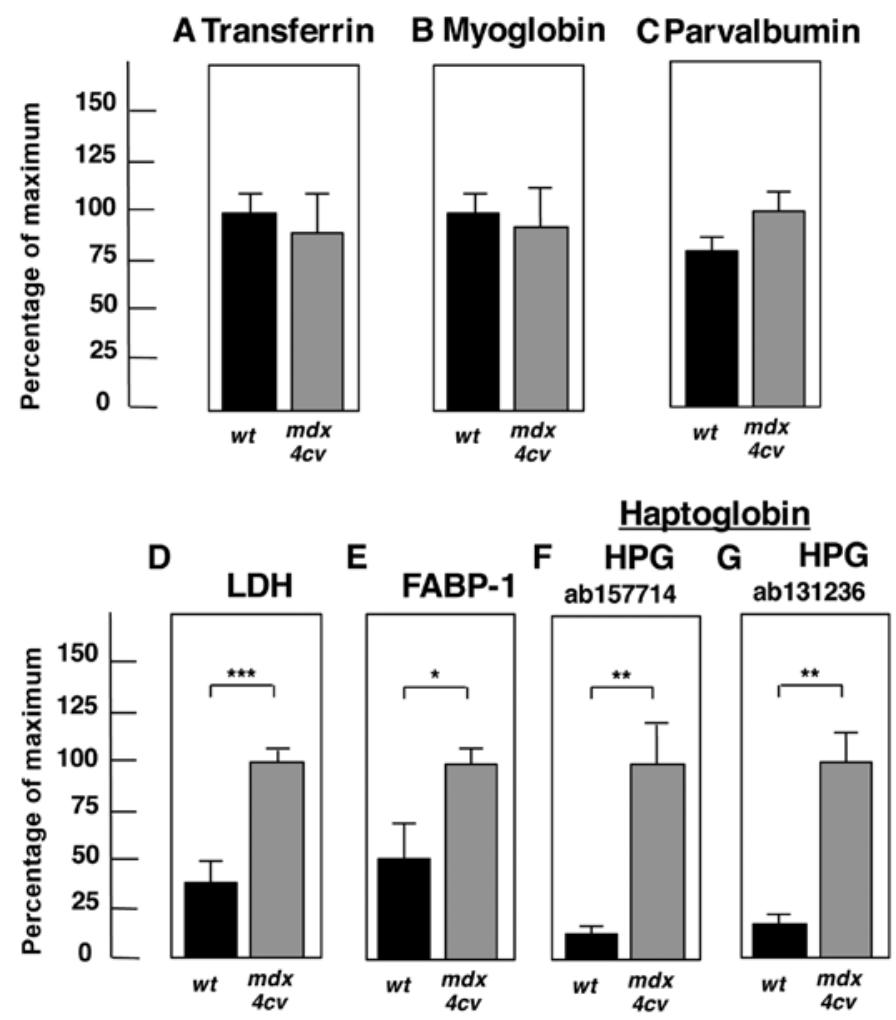

Figure 7. Significant changes of proteins in the $m d x-4 c v$ mouse serum. Shown is the graphical presentation of the statistical evaluation of the immunoblots depicted in Fig. 6 . The comparative blotting between crude serum samples from 6-month-old wild-type (wt) vs. $m d x$ - $4 c v$ mice was statistically evaluated using an unpaired Student's t-test (n=4; $\left.{ }^{*} \mathrm{P}<0.05,{ }^{* *} \mathrm{P}<0.01,{ }^{* * *} \mathrm{P}<0.001\right)$. Shown is the analysis of (A) transferrin, (B) myoglobin, (C) parvalbumin, (D) LDH, (E) FABP-1, and (F and G) HPG. LDH, lactate dehydrogenase; FABP, fatty acid binding protein; HPG, haptoglobin.

Verification of proteomic profiling findings. Following the identification of a large number of altered serum proteins in the $m d x-4 c v$ model of dystrophinopathy, we focused our study on the verification of a few key proteomic findings with a special emphasis on haptoglobin. Proteomic results were confirmed by immunoblotting and enzyme-linked immunosorbent assays with specific antibodies to a select number of serum proteins (Figs. 6-8). The immunoblot analysis of crude serum showed no significant changes in the abundance of serum transferrin, myoglobin and parvalbumin (Fig. 6B-D). In contrast, lactate dehydrogenase and the FABP-1 isoform of fatty acid binding protein exhibited elevated levels in crude $m d x-4 c v$ serum (Figs. 6E and F). Most importantly, the highly increased concentration of serum haptoglobin in dystrophic mice, as shown by mass spectrometric analysis (Table I) was confirmed by immunoblotting with two different antibodies to this acute phase plasma protein (Fig. $6 \mathrm{G}$ and $\mathrm{H}$ ). The statistical evaluation of immunoblotting is summarized in Fig. 7 and establishes the significant elvation of lactate dehydrogenase, fatty acid binding protein FABP-1 and haptoglobin in crude $m d x-4 c v$ serum.

In analogy to immunoblot analyses, enzyme-linked immunosorbent assays with antibodies to haptoglobin and FABP-1 also showed increased levels of these two proteins in crude serum from dystrophic animals (Figs. 8B and C). Statistical ROC analyses demonstrated that these findings were highly significant (Figs. 8D and E). In contrast, values for complement $\mathrm{C} 3$ were found to be comparable between wild-type and $m d x-4 c v$ serum (Fig. 8A).

\section{Discussion}

A key step in the molecular pathogenesis of X-linked muscular dystrophy is mediated by the disintegration of the dystrophin-glycoprotein complex (4) resulting in sarcolemmal destabilisation, impaired cellular signalling, abnormal ion fluxes and increased proteolysis (6). This primary mechanism of fibre damage is accompanied by adaptive responses, such as myofibrosis (10), and secondary changes related to an inflammatory pathology (16). In addition to massive proteome-wide changes within skeletal muscle fibres $(46,50-52,60,72-74)$, the deficiency in dystrophin isoform Dp427 also causes substantial alterations in the rate of protein release from muscle tissues into the circulatory system and other plasma fluctuations (30-39). This includes actively secreted proteins and passively released components from mechanically damaged fibres and other types of tissue (29). In this respect, one of the major findings of the proteomic serum study presented here is the identification of elevated haptoglobin levels in $m d x-4 c v$ serum by mass spectrometry, immunoblotting and enzyme-linked immunosorbent assays.

This acute phase plasma protein is a tissue damage marker and is often increased in serum in relation to cellular degeneration and inflammation (75). Since there is an urgent need to establish new biomarker candidates of X-linked muscular dystrophy (76), the proteomic identification of elevated haptoglobin levels in dystrophinopathy is an encouraging result. Haptoglobin, in conjunction with other altered serum proteins, may represent a novel diagnostic, 
A

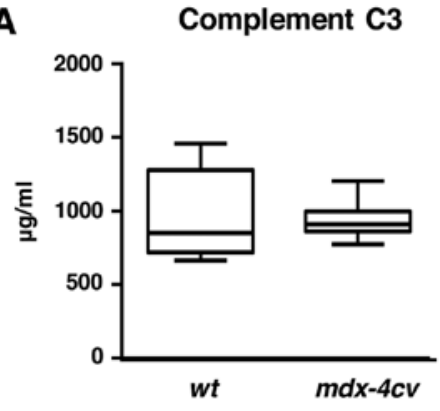

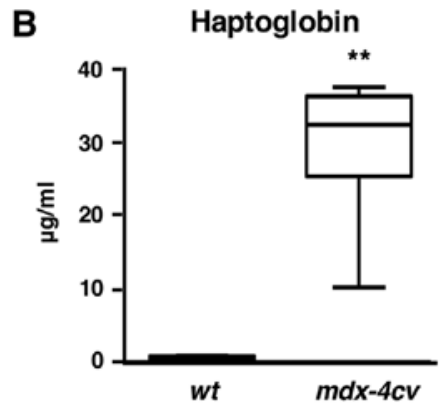

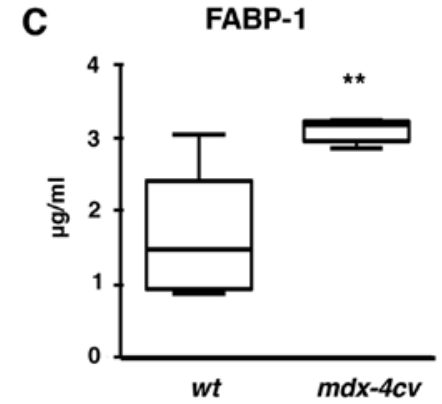

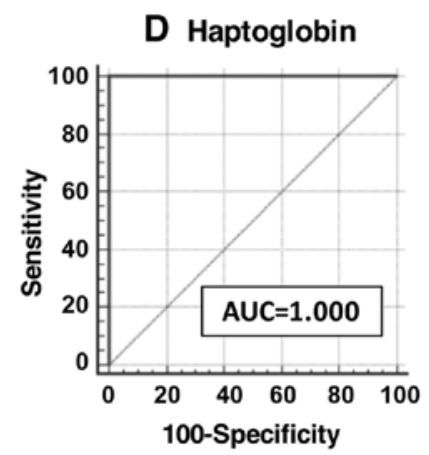

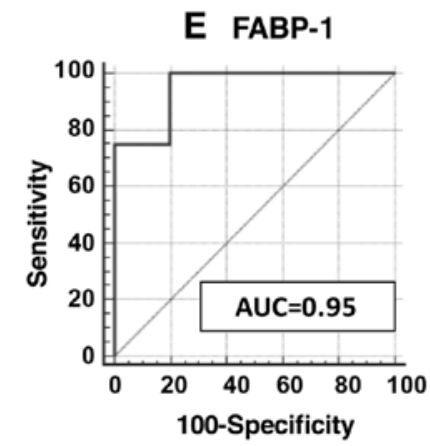

Figure 8. Enzyme-linked immunosorbent assays. Shown are the findings from enzyme-linked immunosorbent assays of crude serum samples that were screened with antibodies to: (A) complement C3, (B) HPG and (C) FABP-1. Statistical analyses using (B and C) the Mann-Whitney U test (wt serum samples: $\mathrm{n}=4 ; m d x-4 c v$ serum samples: $\mathrm{n}=8 ;{ }^{* *} \mathrm{P} \leq 0.01$ and (D and E) statistical ROC curve analyses demonstrated that the increases in (B and D) HPG and (C and E) FABP-1 in $m d x-4 c v$ serum were highly significant. HPG. haptoglobin; FABP, fatty acid binding protein; ROC, receiver operating characteristic.

prognostic and/or therapy-monitoring biomarker candidate for the improved evaluation of sterile inflammation in the $m d x-4 c v$ animal model of dystrophinopathy. Haptoglobin is a major acute phase plasma protein that acts as a high-affinity hemoglobin-binding protein and protective anti-oxidant (77). The liver is the main site of haptoglobin synthesis, but this protein is also produced in other organs (43). The increased serum haptoglobin levels established here by mass spectrometry agree with a pre-proteomic analysis by two-dimensional gel electrophoresis and densitometric scanning by John and Purdom (78). A recent serum proteomic profiling study by Rouillon et al (37) with a focus on the characterization of the myofibrillar structural protein myomesin isoform MYOM3 also identified haptoglobin as a potential biomarker candidate for monitoring the outcome of therapeutic interventions in Duchenne muscular dystrophy.

The cellular disturbances and multi-system pathology of dystrophinopathy are closely associated with highly complex and interconnecting damage pathways, including modifying factors such as abnormal $\mathrm{Ca}^{2+}$ flux, increased proteolytic degradation, elevated extracellular ATP levels and altered cytokine signalling $(6,8)$. In addition to promoting hyperactive extracellular matrix remodelling and resulting fibrotic scarring, these processes stimulate harmful inflammatory responses (79). Macrophages are intrinsically involved in both the natural repair of acutely injured skeletal muscle fibres and the pathological exacerbation of chronically damaged contractile cells (80). Inflammatory monocyte-derived macrophages appear to be closely associated with disturbed chemokine levels and are key cell types that promote changes in dystrophin-deficient and degenerating skeletal muscles $(13,81)$. Sterile tissue injury that occurs chronically in muscular dystrophy initiates a local inflammatory response. This in turn triggers the mobilization of the acute phase reaction causing a massive increase in the level of acute phase plasma proteins in the circulatory system.

As a biomarker of dystrophinopathy, the advantages of serum haptoglobin are manifold as compared to muscle-associated proteins, since the application of diagnostic or prognostic biomarkers associated with the skeletal muscle interior would require the undesirable usage of invasive methodology (62). In contrast, the systematic mining of the biofluid proteome promises to identify novel marker molecules that can be assayed in a minimally invasive or non-invasive manner and may also result in the proteomic identification of new therapeutic targets (82-84). However, it is important to emphasise that the field of predictive and diagnostic medicine has had only limited success in the translation from biomarker discovery to clinical utility, especially in relation to biomarker specificity (85). This would also be a critical issue in the future application of haptoglobin as a biomarker, since this serum protein was recently identified as a novel marker molecule, which is potentially suitable for predicting a variety of human diseases including colorectal cancer hepatic metastasis (86).

In the case of muscular dystrophy, one can assume that damaged and leaky skeletal muscle tissue has an enhanced tendency to actively release or passively shed proteins, metabolites and other biomolecules into their external environment. These factors also trigger secondary changes in other tissue and organ systems in the body and thereby cause considerable plasma fluctuations. The range and density of released protein species relates relatively well to the degree of cellular damage (29). In addition to the effects on acute phase plasma protein concentration, this proteomic study has 
shown that highly complex proteome-wide alterations occur in the serum in a dystrophic organism. As established by the systems bioinformatic analysis of the proteomic $m d x-4 c v$ serum data (56), affected protein families include cytoskeletal proteins, hydrolases, oxidoreductases, transferases, nucleic acid binding proteins, molecular chaperones, proteases, signalling molecules and ion-handling proteins. These proteins with an altered serum concentration are involved in many complex cellular activities, such as energy metabolism, physiological regulation, fibre adaptations, intercellular and intracellular signalling, the stress response, fibre transitions and the excitation-contraction-relaxation cycle. The proteomic findings emphasize the pathobiochemical complexity of the dystrophic phenotype and suggest that future therapeutic approaches have to address a variety of downstream changes from the primary abnormality in the membrane cytoskeleton (3).

In conclusion, the identification of robust and unambiguous biomarkers of high biomedical and clinical value is an important aim of the systematic assessment of pathological specimens related to X-linked muscular dystrophy. Here, we identified elevated levels of the acute phase plasma protein haptoglobin in the serum from dystrophic $m d x-4 c v$ mice as a new potential indicator molecule of the inflammatory phenotype of dystrophinoapthy. Since antibody-based tests have confirmed the significantly increased concentration of serum haptoglobin, this protein represents a solid biomarker candidate. Haptoglobin is easily assessable, exhibits a high diagnostic potential and has suitable physicochemical properties. Hence, this serum protein is an ideal candidate molecule for the future establishment of a sensitive and cost-effective test system to evaluate inflammatory processes related to skeletal muscle damage in muscular dystrophy.

\section{Acknowledgements}

The present research was supported by a Hume scholarship from Maynooth University and project grants from the Deutsche Duchenne Stiftung aktion benni \& co e.V. the Health Research Board and Muscular Dystrophy Ireland. The Q-Exactive quantitative mass spectrometer was funded under the Research Infrastructure Call 2012 by the Science Foundation of Ireland (SFI-12/RI/2346/3).

\section{References}

1. Flanigan KM: Duchenne and Becker muscular dystrophies. Neurol Clin 32: 671-688, viii, 2014.

2. Mah JK, Korngut L, Dykeman J, Day L, Pringsheim T and Jette N: A systematic review and meta-analysis on the epidemiology of Duchenne and Becker muscular dystrophy. Neuromuscul Disord 24: 482-491, 2014.

3. Guiraud S, Aartsma-Rus A, Vieira NM,Davies KE, van Ommen GJ and Kunkel LM: The pathogenesis and therapy of muscular dystrophies. Annu Rev Genomics Hum Genet 16: 281-308, 2015.

4. Ohlendieck K: Towards an understanding of the dystrophin-glycoprotein complex: Linkage between the extracellular matrix and the membrane cytoskeleton in muscle fibers. Eur J Cell Biol 69: $1-10,1996$.

5. Allen DG, Zhang BT and Whitehead NP: Stretch-induced membrane damage in muscle: Comparison of wild-type and $\mathrm{mdx}$ mice. Adv Exp Med Biol 682: 297-313, 2010.

6. Allen DG, Whitehead NP and Froehner SC: Absence of dystrophin disrupts skeletal muscle signaling: Roles of $\mathrm{Ca}^{2+}$, reactive oxygen species, and nitric oxide in the development of muscular dystrophy. Physiol Rev 96: 253-305, 2016.
7. Hopf FW, Turner PR and Steinhardt RA: Calcium misregulation and the pathogenesis of muscular dystrophy. Subcell Biochem 45: 429-464, 2007.

8. Shin J, Tajrishi MM, Ogura Y and Kumar A: Wasting mechanisms in muscular dystrophy. Int J Biochem Cell Biol 45: 2266-2279, 2013.

9. Mázala DA, Grange RW and Chin ER: The role of proteases in excitation-contraction coupling failure in muscular dystrophy. Am J Physiol Cell Physiol 308: C33-C40, 2015.

10. Holland A, Murphy S, Dowling P and Ohlendieck K: Pathoproteomic profiling of the skeletal muscle matrisome in dystrophinopathy associated myofibrosis. Proteomics 16: 345-366, 2016.

11. Serra F, Quarta M, Canato M, Toniolo L, De Arcangelis V, Trotta A, Spath L, Monaco L, Reggiani C and Naro F: Inflammation in muscular dystrophy and the beneficial effects of non-steroidal anti-inflammatory drugs. Muscle Nerve 46: 773-784, 2012.

12. De Paepe B and De Bleecker JL: Cytokines and chemokines as regulators of skeletal muscle inflammation: Presenting the case of Duchenne muscular dystrophy. Mediators Inflamm 2013: $540370,2013$.

13. Mojumdar K, Liang F, Giordano C, Lemaire C, Danialou G, Okazaki T, Bourdon J, Rafei M, Galipeau J, Divangahi M and Petrof BJ: Inflammatory monocytes promote progression of Duchenne muscular dystrophy and can be therapeutically targeted via CCR2. EMBO Mol Med 6: 1476-1492, 2014.

14. Villalta SA, Rosenberg AS and Bluestone JA: The immune system in Duchenne muscular dystrophy: Friend or foe. Rare Dis 3: e1010966, 2015

15. Tidball JG: Mechanisms of muscle injury, repair, and regeneration. Compr Physiol 1: 2029-2062, 2011.

16. Rosenberg AS, Puig M, Nagaraju K, Hoffman EP, Villalta SA, Rao VA, Wakefield LM and Woodcock J: Immune-mediated pathology in Duchenne muscular dystrophy. Sci Transl Med 7: 299rv4, 2015.

17. Villalta SA, Rosenthal W, Martinez L, Kaur A, Sparwasser T, Tidball JG, Margeta M, Spencer MJ and Bluestone JA: Regulatory T cells suppress muscle inflammation and injury in muscular dystrophy. Sci Transl Med 6: 258ra142, 2014.

18. Proud CM: 50 years ago in the Journal of Pediatrics: The use of serum creatine phosphokinase and other serum enzymes in the diagnosis of progressive muscular dystrophy. J Pediatr 163: $1656,2013$.

19. Percy ME, Andrews DF and Thompson MW: Duchenne muscular dystrophy carrier detection using logistic discrimination: Serum creatine kinase, hemopexin, pyruvate kinase, and lactate dehydrogenase in combination. Am J Med Genet 13: 27-38, 1982.

20. Carter ND, Heath R, Jeffery S, Jackson MJ, Newham DJ and Edwards RH: Carbonic anhydrase III in Duchenne muscular dystrophy. Clin Chim Acta 133: 201-208, 1983.

21. Fröhlich T, Reitter B, Scheffner D, Schirmer RH and Untucht-Grau R: Muscle adenylate kinase in Duchenne muscular dystrophy. Biochim Biophys Acta 883: 598-603, 1986.

22. Percy ME, Chang LS, Murphy EG, Oss I, Verellen-Dumoulin C and Thompson MW: Serum creatine kinase and pyruvate kinase in Duchenne muscular dystrophy carrier detection. Muscle Nerve 2: 329-339, 1979.

23. D'Amore PA, Brown RH Jr, Ku PT, Hoffman EP, Watanabe H, Arahata K, Ishihara T and Folkman J: Elevated basic fibroblast growth factor in the serum of patients with Duchenne muscular dystrophy. Ann Neurol 35: 362-365, 1994.

24. Bernasconi P, Torchiana E, Confalonieri P, Brugnoni R, Barresi R, Mora M, Cornelio F, Morandi L and Mantegazza R: Expression of transforming growth factor-beta 1 in dystrophic patient muscles correlates with fibrosis. Pathogenetic role of a fibrogenic cytokine. J Clin Invest 96: 1137-1144, 1995.

25. Sun G, Haginoya K, Chiba Y, Uematsu M, Hino-Fukuyo N, Tanaka S, Onuma A, Iinuma K and Tsuchiya S: Elevated plasma levels of tissue inhibitors of metalloproteinase-1 and their overexpression in muscle in human and mouse muscular dystrophy. J Neurol Sci 297: 19-28, 2010.

26. Nadarajah VD, van Putten M, Chaouch A, Garrood P, Straub V, Lochmüller H, Ginjaar HB, Aartsma-Rus AM, van Ommen GJ, den Dunnen JT and 't Hoen PA: Serum matrix metalloproteinase-9 (MMP-9) as a biomarker for monitoring disease progression in Duchenne muscular dystrophy (DMD). Neuromuscul Disord 21: 569-578, 2011.

27. Holland A, Carberry S and Ohlendieck K: Proteomics of the dystrophin-glycoprotein complex and dystrophinopathy. Curr Protein Pept Sci 14: 680-697, 2013. 
28. Fuller HR, Graham LC, Llavero Hurtado M and Wishart TM: Understanding the molecular consequences of inherited muscular dystrophies: Advancements through proteomic experimentation. Expert Rev Proteomics 13: 659-671, 2016.

29. Hathout Y, Seol H, Han MH, Zhang A, Brown KJ and Hoffman EP: Clinical utility of serum biomarkers in Duchenne muscular dystrophy. Clin Proteomics 13: 9, 2016.

30. Alagaratnam S, Mertens BJ, Dalebout JC, Deelder AM, van Ommen GJ, den Dunnen JT and 't Hoen PA: Serum protein profiling in mice: Identification of Factor XIIIa as a potential biomarker for muscular dystrophy. Proteomics 8: 1552-1563, 2008.

31. Duguez S, Duddy W,Johnston H,Lainé J,Le Bihan MC, Brown KJ, Bigot A, Hathout Y, Butler-Browne G and Partridge T: Dystrophin deficiency leads to disturbance of LAMP1-vesicle-associated protein secretion. Cell Mol Life Sci 70: 2159-2174, 2013.

32. Hathout Y, Marathi RL, Rayavarapu S, Zhang A, Brown KJ Seol H, Gordish-Dressman H, Cirak S, Bello L, Nagaraju K, et al: Discovery of serum protein biomarkers in the mdx mouse model and cross-species comparison to Duchenne muscular dystrophy patients. Hum Mol Genet 23: 6458-6469, 2014.

33. Cynthia Martin F, Hiller M, Spitali P, Oonk S, Dalebout H, Palmblad M,Chaouch A, Guglieri M, Straub V,LochmüllerH, et al: Fibronectin is a serum biomarker for Duchenne muscular dystrophy. Proteomics Clin Appl 8: 269-278, 2014.

34. Ayoglu B, Chaouch A, Lochmüller H, Politano L, Bertini E, Spitali P, Hiller M, Niks EH, Gualandi F, Pontén F, et al: Affinity proteomics within rare diseases: A BIO-NMD study for blood biomarkers of muscular dystrophies. EMBO Mol Med 6: 918-936, 2014.

35. Rouillon J, Zocevic A, Leger T, Garcia C, Camadro JM, Udd B, Wong B, Servais L, Voit T and Svinartchouk F: Proteomics profiling of urine reveals specific titin fragments as biomarkers of Duchenne muscular dystrophy. Neuromuscul Disord 24: 563-573, 2014.

36. Coenen-Stass AM, McClorey G, Manzano R, Betts CA, Blain A, Saleh AF, Gait MJ, Lochmüller H, Wood MJ and Roberts TC: Identification of novel, therapy-responsive protein biomarkers in a mouse model of Duchenne muscular dystrophy by aptamer-based serum proteomics. Sci Rep 5: 17014, 2015.

37. Rouillon J, Poupiot J, Zocevic A, Amor F, Léger T, Garcia C, Camadro JM, Wong B, Pinilla R, Cosette J, et al: Serum proteomic profiling reveals fragments of MYOM3 as potential biomarkers for monitoring the outcome of therapeutic interventions in muscular dystrophies. Hum Mol Genet 24: 4916-4932, 2015.

38. Hathout Y, Brody E, Clemens PR, Cripe L, DeLisle RK, Furlong P Gordish-Dressman H, Hache L, Henricson E, Hoffman EP, et al: Large-scale serum protein biomarker discovery in Duchenne muscular dystrophy. Proc Natl Acad Sci USA 112: 7153-7158, 2015.

39. Oonk S, Spitali P, Hiller M, Switzar L, Dalebout H, Calissano M, Lochmüller H, Aartsma-Rus A, 't Hoen PA and van der Burgt YE: Comparative mass spectrometric and immunoassay-based proteome analysis in serum of Duchenne muscular dystrophy patients. Proteomics Clin Appl 10: 290-299, 2016.

40. Im WB, Phelps SF, Copen EH, Adams EG, Slightom JL and Chamberlain JS: Differential expression of dystrophin isoforms in strains of mdx mice with different mutations. Hum Mol Genet 5: 1149-1153, 1996

41. Danko I, Chapman V and Wolff JA: The frequency of revertants in mdx mouse genetic models for Duchenne muscular dystrophy. Pediatr Res 32: 128-131, 1992.

42. Mitrpant C, Fletcher S, Iversen PL and Wilton SD: By-passing the nonsense mutation in the $4 \mathrm{CV}$ mouse model of muscular dystrophy by induced exon skipping. J Gene Med 11: 46-56, 2009.

43. Wang Y, Kinzie E, Berger FG, Lim SK and Baumann H: Haptoglobin, an inflammation-inducible plasma protein. Redox Rep 6: 379-385, 2001.

44. Chapman VM, Miller DR, Armstrong D and Caskey CT: Recovery of induced mutations for X chromosome-linked muscular dystrophy in mice. Proc Natl Acad Sci USA 86 1292-1296, 1989

45. Partridge TA: The mdx mouse model as a surrogate for Duchenne muscular dystrophy. FEBS J 280: 4177-4186, 2013

46. Carberry S, Zweyer M, Swandulla D and Ohlendieck K: Comparative proteomic analysis of the contractile-proteindepleted fraction from normal versus dystrophic skeletal muscle. Anal Biochem 446: 108-115, 2014.
47. Hortin GL and Sviridov D: The dynamic range problem in the analysis of the plasma proteome. J Proteomics 73: 629-636, 2010.

48. Anderson NL and Anderson NG: The human plasma proteome: History, character, and diagnostic prospects. Mol Cell Proteomics 1: 845-867, 2002.

49. Bradford MM: A rapid and sensitive method for the quantitation of microgram quantities of protein utilizing the principle of protein-dye binding. Anal Biochem 72: 248-254, 1976.

50. Holland A, Henry M, Meleady P, Winkler CK, Krautwald M, Brinkmeier $\mathrm{H}$ and Ohlendieck K: Comparative label-free mass spectrometric analysis of mildly versus severely affected $\mathrm{mdx}$ mouse skeletal muscles identifies annexin, lamin, and vimentin as universal dystrophic markers. Molecules 20: 11317-11344, 2015.

51. Holland A, Dowling P, Meleady P, Henry M, Zweyer M, Mundegar RR, Swandulla D and Ohlendieck K: Label-free mass spectrometric analysis of the $m d x-4 c v$ diaphragm identifies the matricellular protein periostin as a potential factor involved in dystrophinopathy-related fibrosis. Proteomics 15: 2318-2331, 2015.

52. Murphy S, Zweyer M, Mundegar RR, Henry M, Meleady P, Swandulla D and Ohlendieck K: Concurrent label-free mass spectrometric analysis of dystrophin isoform Dp427 and the myofibrosis marker collagen in crude extracts from $m d x-4 c v$ skeletal muscles. Proteomes 3: 298-327, 2015.

53. Di Luca A, Henry M, Meleady P and O'Connor R: Label-free LC-MS analysis of HER $2^{+}$breast cancer cell line response to HER2 inhibitor treatment. Daru 23: 40, 2015.

54. Linge A, Maurya P, Friedrich K, Baretton GB, Kelly S, Henry M, Clynes M, Larkin A and Meleady P: Identification and functional validation of RAD23B as a potential protein in human breast cancer progression. J Proteome Res 13: 3212-3222, 2014.

55. Murphy S, Dowling P, Zweyer M, Mundegar RR, Henry M, Meleady P, Swandulla D and Ohlendieck K: Proteomic analysis of dystrophin deficiency and associated changes in the aged $m d x-4 c v$ heart model of dystrophinopathy-related cardiomyopathy. J Proteomics 145: 24-36, 2016.

56. Mi H, Muruganujan A and Thomas PD: PANTHER in 2013: Modeling the evolution of gene function, and other gene attributes, in the context of phylogenetic trees. Nucleic Acids Res 41 (D1): D377-D386, 2013.

57. Staunton L, Zweyer M, Swandulla D and Ohlendieck K: Mass spectrometry-based proteomic analysis of middle-aged vs. aged vastus lateralis reveals increased levels of carbonic anhydrase isoform 3 in senescent human skeletal muscle. Int J Mol Med 30: 723-733, 2012

58. Holland A, Dowling P, Zweyer M, Swandulla D, Henry M, Clynes $\mathrm{M}$ and Ohlendieck K: Proteomic profiling of cardiomyopathic tissue from the aged mdx model of Duchenne muscular dystrophy reveals a drastic decrease in laminin, nidogen and annexin. Proteomics 13: 2312-2323, 2013.

59. Lewis C, Jockusch H and Ohlendieck K: Proteomic profiling of the dystrophin-deficient MDX heart reveals drastically altered levels of key metabolic and contractile proteins. J Biomed Biotechnol 2010: 648501, 2010.

60. Murphy S, Henry M, Meleady P, Zweyer M, Mundegar RR, Swandulla D and Ohlendieck K: Simultaneous pathoproteomic evaluation of the dystrophin-glycoprotein complex and secondary changes in the $m d x-4 c v$ mouse model of Duchenne muscular dystrophy. Biology (Basel) 4: 397-423, 2015.

61. Murphy S, Zweyer M, Henry M, Meleady P, Mundegar RR, Swandulla D and Ohlendieck K: Label-free mass spectrometric analysis reveals complex changes in the brain proteome from the $m d x-4 c v$ mouse model of Duchenne muscular dystrophy. Clin Proteomics 12: 27, 2015.

62. Dowling P, Holland A and Ohlendieck K: Mass spectrometry-based identification of muscle-associated and muscle-derived proteomic biomarkers of dystrophinopathies. J Neuromuscul Dis 1: 15-40, 2014.

63. Gianazza E, Miller I, Palazzolo L, Parravicini C and Eberini I: With or without you - Proteomics with or without major plasma/serum proteins. J Proteomics 140: 62-80, 2016.

64. Omenn GS, States DJ, Adamski M, Blackwell TW, Menon R, Hermjakob H, Apweiler R, Haab BB, Simpson RJ, Eddes JS, et al: Overview of the HUPO Plasma Proteome Project: Results from the pilot phase with 35 collaborating laboratories and multiple analytical groups, generating a core dataset of 3020 proteins and a publicly-available database. Proteomics 5: 3226-3245, 2005. 
65. Pietrowska M, Marczak L, Polanska J, Behrendt K, Nowicka E, Walaszczyk A, Chmura A, Deja R, Stobiecki M, Polanski A, et al: Mass spectrometry-based serum proteome pattern analysis in molecular diagnostics of early stage breast cancer. J Transl Med 7: 60, 2009.

66. Smith MP, Wood SL, Zougman A, Ho JT, Peng J, Jackson D, Cairns DA, Lewington AJ, Selby PJ and Banks RE: A systematic analysis of the effects of increasing degrees of serum immunodepletion in terms of depth of coverage and other key aspects in top-down and bottom-up proteomic analyses. Proteomics 11: 2222-2235, 2011.

67. Dowling P, Hayes C, Ting KR, Hameed A, Meiller J, Mitsiades C, Anderson KC, Clynes M, Clarke C, Richardson P and O'Gorman P: Identification of proteins found to be significantly altered when comparing the serum proteome from Multiple Myeloma patients with varying degrees of bone disease. BMC Genomics 15: 904, 2014.

68. Araújo JE, Jorge S, Teixeira E Costa F, Ramos A, Lodeiro C, Santos HM and Capelo JL: A cost-effective method to get insight into the peritoneal dialysate effluent proteome. J Proteomics 145: 207-213, 2016.

69. Gundry RL, Fu Q, Jelinek CA, Van Eyk JE and Cotter RJ Investigation of an albumin-enriched fraction of human serum and its albuminome. Proteomics Clin Appl 1: 73-88, 2007.

70. Gundry RL, White MY, Nogee J, Tchernyshyov I and Van Eyk JE: Assessment of albumin removal from an immunoaffinity spin column: Critical implications for proteomic examination of the albuminome and albumin-depleted samples. Proteomics 9: 2021-2028, 2009.

71. Tirumalai RS, Chan KC, Prieto DA, Issaq HJ, Conrads TP and Veenstra TD: Characterization of the low molecular weight human serum proteome. Mol Cell Proteomics 2: 1096-1103, 2003.

72. Rayavarapu S, Coley W, Cakir E, Jahnke V, Takeda S, Aoki Y, Grodish-Dressman H, Jaiswal JK, Hoffman EP, Brown KJ, et al: Identification of disease specific pathways using in vivo SILAC proteomics in dystrophin deficient mdx mouse. Mol Cell Proteomics 12: 1061-1073, 2013.

73. Roberts TC, Johansson HJ, McClorey G, Godfrey C Blomberg KE, Coursindel T, Gait MJ, Smith CI, Lehtiö J, El Andaloussi S and Wood MJ: Multi-level omics analysis in a murine model of dystrophin loss and therapeutic restoration. Hum Mol Genet 24: 6756-6768, 2015.
74. Turk R, Hsiao JJ, Smits MM, Ng BH, Pospisil TC, Jones KS, Campbell KP and Wright ME: Molecular signatures of membrane protein complexes underlying muscular dystrophy. Mol Cell Proteomics 15: 2169-2185, 2016.

75. Schrödl W, Büchler R, Wendler S, Reinhold P, Muckova P, Reindl J and Rhode $\mathrm{H}$ : Acute phase proteins as promising biomarkers: Perspectives and limitations for human and veterinary medicine. Proteomics Clin Appl 10: 1077-1092, 2016.

76. Ohlendieck K: Proteomic identification of biomarkers of skeletal muscle disorders. Biomarkers Med 7: 169-186, 2013.

77. Levy AP, Asleh R, Blum S, Levy NS, Miller-Lotan R, Kalet-Litman S, Anbinder Y, Lache O, Nakhoul FM, Asaf, et al: Haptoglobin: Basic and clinical aspects. Antioxid Redox Signal 12: 293-304, 2010.

78. John HA and Purdom IF: Elevated plasma levels of haptoglobin in Duchenne muscular dystrophy: Electrophoretic variants in patients with a severe form of the disease. Electrophoresis 10: 489-493, 1989.

79. Górecki DC: Dystrophin: The dead calm of a dogma. Rare Dis 4: e1153777, 2016.

80. Kharraz Y,Guerra J,Mann CJ, Serrano AL and Muñoz-Cánoves P: Macrophage plasticity and the role of inflammation in skeletal muscle repair. Mediators Inflamm 2013: 491497, 2013.

81. Sinadinos A, Young CN, Al-Khalidi R, Teti A, Kalinski P, Mohamad S, Floriot L, Henry T, Tozzi G, Jiang T, et al: P2RX7 purinoceptor: A therapeutic target for ameliorating the symptoms of duchenne muscular dystrophy. PLoS Med 12: e1001888, 2015.

82. Veenstra TD, Conrads TP, Hood BL, Avellino AM, Ellenbogen RG and Morrison RS: Biomarkers: Mining the biofluid proteome. Mol Cell Proteomics 4: 409-418, 2005.

83. Savino R, Paduano S, Preianò $M$ and Terracciano R: The proteomics big challenge for biomarkers and new drug-targets discovery. Int J Mol Sci 13: 13926-13948, 2012.

84. Stastna M and Van Eyk JE: Secreted proteins as a fundamental source for biomarker discovery. Proteomics 12: 722-735, 2012.

85. Drucker E and Krapfenbauer K: Pitfalls and limitations in translation from biomarker discovery to clinical utility in predictive and personalised medicine. EPMA J 4: 7, 2013.

86. Sun L, Hu S, Yu L, Guo C, Sun L, Yang Z, Qi J and Ran Y: Serum haptoglobin as a novel molecular biomarker predicting colorectal cancer hepatic metastasis. Int J Cancer 138: 2724-2731, 2016. 